\title{
MISI KRISTEN DI INDONESIA: KESAKSIAN KRISTEN PROTESTAN
}

\author{
Benyamin F. Intan \\ Sekolah Tinggi Teologi Reformed Injili Internasional
}

\begin{abstract}
In this article, the writer states the presence and struggles of Protestant churches in Indonesia doing God's mission within world's largest Muslim population country. Firstly, the writer explains the challenges and strives of Protestant churches from the time of Dutch colonialism, Japanese colonization, until Indonesian independence which includes the Old Order and the New Order. This article also highlights Indonesian churches' struggle of independence to release themselves from the control of Dutch government, fully leaning to Christ, as well as the strategic role of Christianity in preventing nation's disintegration to make Indonesia one. After that, the writer then performs critical reflection on the struggles of Protestant churches in Indonesia from the perspective of Reformed theology. The writer found that the presence of Christian mission in Indonesia is far from the force of arms and economic greed. However, churches in Indonesia cannot detach themselves from various challenges and suffering in God's mission which includes Evangelical Mandate and Cultural Mandate. Therefore, while they are still entrusted by Christ, churches in Indonesia ought to perform their dutiful calling faithfully and joyfully.
\end{abstract}


KEYWORDS: God's mission, witness, evangelism, protestant church in Indonesia, ideology, religion-state relation, mission's institution

ABSTRAK: Dalam artikel ini, penulis mengungkapkan kehadiran dan pergumulan gereja-gereja Protestan di Indonesia di dalam menjalankan misi Allah di negara yang memiliki penduduk Muslim terbesar di seluruh dunia. Pertama-tama, penulis memaparkan tantangan dan perjuangan gereja-gereja Protestan sejak masa kolonialisme Belanda, penjajahan Jepang, hingga Indonesia merdeka yang mencakup Orde Lama dan Orde Baru. Artikel ini juga menyoroti perjuangan kemandirian gereja-gereja di Indonesia di dalam melepaskan diri dari kendali pemerintahan Belanda, bersandar sepenuhnya kepada Kristus, serta peran strategis kekristenan di dalam mencegah perpecahan bangsa untuk mewujudkan Indonesia yang satu. Setelah itu penulis kemudian melakukan refleksi kritis terhadap pergumulan gereja-gereja Protestan di Indonesia dari perspektif teologi Reformed. Penulis menemukan bahwa kehadiran misi Kristen di Indonesia jauh dari kekuatan senjata dan ketamakan ekonomi. Namun, gereja-gereja di Indonesia tidak dapat melepaskan dirinya dari berbagai tantangan dan penderitaan dalam menjalankan misi Allah yang mencakup Mandat Injili dan Mandat Budaya. Untuk itu, selama masih diberikan kepercayaan oleh Kristus, gereja-gereja Indonesia harus menjalankan tugas panggilannya dengan setia dan sukacita. 
KATA KUNCI: Misi Allah, kesaksian, penginjilan, gereja protestan di Indonesia, ideologi, hubungan agama-negara, lembaga misi.

\section{INTRODUKSI}

Penyebaran agama yang bersandar pada kekuatan senjata dan disertai ketamakan ekonomi bukan hanya akan gagal tapi juga akan menjadi kontraproduktif bagi agama tersebut. Tidak gampang memang bagi kekristenan Indonesia untuk hadir dan bersaksi di bumi pertiwi mengingat Indonesia selama 350 tahun dijajah kolonialisme Belanda yang notabene membawa agama Kristen. Bagaimana caranya agar gereja-gereja Protestan yang tadinya 'gereja kolonial' dapat menjadi 'gereja etnis' dan kemudian menjadi 'gereja Indonesia'? Hanya anugerah Tuhan semata jika gereja-gereja Protestan dapat menjadikan Indonesia ladang misi untuk bersaksi dan menggumuli panggilannya. Untuk mendapatkan gambaran yang utuh tentang hal ini, dalam artikel ini penulis akan membahas tantangan dan perjuangan gereja-gereja Protestan sejak masa kolonialisme Belanda, penjajahan Jepang, hingga Indonesia Merdeka yang mencakup Orde Lama dan Orde Baru. Penulis kemudian akan melakukan refleksi kritis terhadap pergumulan gereja-gereja Protestan di Indonesia dari perspektif teologi Reformed.

\section{KOLONIALISME BELANDA (1602-1942)}

Masuknya kekristenan ke Indonesia pada abad ke-16 dimulai dengan penyebaran agama Katolik oleh Portugis, kemudian diikuti Belanda yang membawa agama Protestan 
pada awal abad ke-17. ${ }^{1}$ Pada saat itu, Islam yang sedang gencar-gencarnya berekspansi, mendesak Hindu pindah dari Jawa ke Bali. ${ }^{2}$ Dengan demikian, sebelum Islam menyebar di seluruh Indonesia, kekristenan hadir dengan menancapkan kukunya di daerah-daerah yang belum dimasuki Islam seperti Maluku dan Timor. Belanda yang merupakan musuh Portugis "politically, commercially, and religiously", menghancurkan kekuatan Portugis di daerah-daerah tersebut dan mengkonversi agama penduduknya dari Katolik ke Protestan. ${ }^{3}$

Penyebaran misi Protestan oleh kolonialisme Belanda di Indonesia dapat dibagi menjadi dua tahap: tahap pertama melalui Vereenigde Oost-Indische Compagnie (VOC, United East Indies Company) tahun 1602-1799 dan tahap kedua melalui the Dutch East Indies tahun 1800-1942.

\section{VOC (1602-1799)}

Kehadiran kolonialisme Belanda di Indonesia melalui VOC (1602-1799) memiliki motivasi utama mencari rempahrempah. Pada awalnya, dalam ikatan kontrak antara

${ }^{1}$ Lihat Th. Müller Krüger, Sedjarah Geredja di Indonesia, edisi kedua (Jakarta: Badan penerbit Kristen, 1966).

2 Islam masuk Indonesia sekitar akhir abad ke-13. Ketika Marco Polo mengunjungi Aceh akhir abad ke-13, ia menyaksikan kehadiran Islam di beberapa pusat perdagangan. T.B. Simatupang, "Doing Theology in Indonesia Today", CTC Bulletin 3, no. 2 (Agustus 1982): 22.

${ }^{3}$ T.B. Simatupang, "Dynamics for Creative Maturity", dalam Asian Voices in Christian Theology, ed. Gerald H. Anderson (Maryknoll: Orbis Books, 1976), 91. 
pemerintah Belanda dan VOC tidak ada pasal tentang kekristenan, namun pada tahun 1623 VOC diharuskan menyebarkan misi Kristen. ${ }^{4}$ Itu sebabnya dalam struktur VOC, misi kekristenan masuk dan menjadi bagian dari "Department of Trade and Colonies" kemudian pindah ke departemen baru yang dinamakan "Department of Education, Worship and Industry". ${ }^{5}$ Dengan demikian, motif perdagangan VOC tidak bisa dilepaskan dari misi pekabaran Injil karena pada saat itu Belanda menganut prinsip cuius regio eius religio (siapa memerintah, agamanya yang dianut). Seperti dinyatakan dalam artikel 36 Pengakuan Iman Belanda bahwa pemerintah berkewajiban "untuk memelihara Geredja jang kudus, untuk melawan serta memberantas segala agama palsu dan penjembahan berhala, untuk memusnahkan keradjaan antikrist dan memadjukan keradjaan Jesus". ${ }^{6}$ Dengan kata lain, terjadi penyatuan gereja dan negara. Dengan demikian, gereja yang berdiri pada jaman VOC adalah "Geredja Negara"."

Karena motif utama VOC dalam perdagangan, maka dukungan terhadap penyebaran misi Protestan sejauh

${ }^{4}$ Karel Steenbrink, "The Arrival of Protestantism and the Consolidation of Christianity in the Moluccas 1605-1800" dalam A History of Christianity in Indonesia, eds. Jan Sihar Aritonang dan Karel Steenbrink (Leiden and Boston: E.J. Brill, 2008), 99-100.

${ }^{5}$ Gerry van Klinken, Minorities, Modernity and the Emerging Nation: Christians in Indonesia, a Biographical Approach (Leiden: KITLV Press, 2003), 910 .

${ }^{6}$ Krüger, Sedjarah Geredja di Indonesia, 30.

${ }^{7}$ Ibid., 31. 
mendatangkan profit. Setelah menghancurkan kekuatan Portugis, pengkonversian agama penduduk dari Katolik ke Protestan sangat perlu agar loyalitas penduduk berpindah dari Portugis ke Belanda. Katolik yang sebelumnya berada di berbagai daerah kekuasaan Portugis dikonversi ke Protestan kecuali Katolik di Flores dan pulau-pulau sekitar karena tidak menguntungkan secara ekonomis. ${ }^{8}$ Ds. Wiltens, salah seorang pendeta pertama di Maluku, menulis pada tahun 1615,

Orang2 Kristen setjara nama merupakan keuntungan bagi Kompeni jaitu bahwa dengan dikristenkannja mereka itu maka kompeni dapat menaklukkan banyak rakjat. Sebab apabila ditaklukkan negeri2 dimana rakjatnja sudah dibaptis, maka mereka berada dibawah kedaulatan kita, djika tidak maka mereka berada dibawah kekuasaan bangsa Moro (Islam) jang berperang dengan kita. ${ }^{9}$

Karena misi Protestan menguntungkan kolonialisme Belanda secara ekonomi dan politik, maka selama pemerintahannya 1602-1800, VOC telah mengirimkan pendeta sebanyak 254 orang dan konselor Kristen sebesar 800 orang. Selain itu, VOC menanggung semua kebutuhan gereja termasuk gaji pendeta dan konselor Kristen, pembangunan

8 John Titaley, "From Abandonment to Blessing: the Theological Presence of Christianity in Indonesia", dalam Christian Theology in Asia, ed., Sebastian C.H. Kim (New York: Cambridge University Press, 2008), 74.

${ }^{9}$ Krüger, Sedjarah Geredja di Indonesia, 31-32. 
gedung gereja, dan penerbitan buku-buku rohani yang dibutuhkan. ${ }^{10}$

Karena berorientasi pada keuntungan politik dan ekonomi, maka misi Protestan menghasilkan nominal Kristen. Menurut Th. Müller Krüger, Ds. Wiltens, seperti yang telah disebutkan di atas, pada tahun 1615 banyak mengeluh tentang "orang2 jang namanja sadja Kristen" ${ }^{11}$ Nominal Kristen akan menghasilkan sinkretisme. Itu sebabnya tidak heran jika di Maluku muncul "agama Ambon" yang merupakan "a mixture of Christianity...and traditional religion". ${ }^{12}$ Seperti dikatakan Karel Steenbrink,

The formal conversion to Christianity did not mean a total change in the life and rituals of the new Christians....For many situations in daily life, on the occasion of birth, marriage, burials, harvest, earthquakes or other natural disasters, it was still the traditional religion that often was resorted to. ${ }^{13}$

Karena berada di bawah bayang-bayang kolonialisme, maka misi Protestan tidak pernah terpikirkan untuk mengkontekstualisasikan pengajaran teologi. Teologi yang diajarkan sangat berorientasi Barat. "Thought patterns brought by European missionaries or by the western church", seperti

\footnotetext{
${ }^{10}$ Ibid., 31.

${ }^{11}$ Ibid.

${ }^{12}$ Steenbrink, "The Arrival of Protestantism", 109.

${ }^{13}$ Ibid., 108.
} 
dinyatakan John M. Prior dan Alle Hoekema, "were considered normative. Misionaries were often afraid of heterodox thinking by indigenous believers and suppressed their ideas." ${ }^{14}$ Dengan kata lain, misi Protestan menolak berbagai upaya "indigenous theologising". ${ }^{15}$ Tidak heran, hingga tahun 1800, sekalipun sudah hadir sekitar 200-an tahun, kekristenan belum menjadi milik gereja-gereja di Indonesia. Krüger menyebut kekristenan Indonesia pada saat itu sebagai "Church of people under age". ${ }^{16}$ Begitu terpengaruhnya misi Protestan terhadap kolonialisme Belanda menyebabkan teologi yang dipopulerkan pada saat itu merupakan teologi yang bersifat pietisme. Teologi pietis sangat menekankan hal-hal yang bersifat "personalistic, spiritualistic, otherworldly, and futuristic understanding of Christian faith and life". ${ }^{17}$ Teologi demikian menekankan kesalehan dan penghayatan iman pribadi tetapi tidak

${ }^{14}$ John M. Prior and Alle Hoekema, "Theological Thinking by Indonesian Christians 1850-2000", dalam A History of Christianity in Indonesia, eds. Jan Sihar Aritonang dan Karel Steenbrink (Leiden and Boston: E.J. Brill, 2008), 749.

15 Ibid.

${ }^{16}$ Th. Müller Krüger, ed., Indonesia Raja (Bad Salzuflen: MBK-Verlag, 1966), 99. Dikutip dari Simatupang, "Dynamics for Creative Maturity", 91.

${ }^{17}$ Simatupang, "Dynamics for Creative Maturity", 94. Bdk. deskripsi Frank L. Cooley tentang Kristen Maluku, “Das Gesicht der ältesten evangelischen Kirche in Asien" dalam Krüger, Indonesia Raja, 117-30. Dikutip dari Simatupang, "Dynamics for Creative Maturity”, 115. 
mempedulikan keadilan sosial. ${ }^{18}$ Akibatnya, misi Protestan menutup mata dan acuh tak acuh terhadap sepak terjang kolonialisme Belanda.

Dengan demikian, dapat disimpulkan bahwa misi Protestan yang berada dalam cengkeraman kekuasaan VOC bukan hanya tidak efektif tapi juga kontraproduktif terhadap misi itu sendiri. Dengan bersikap diam terhadap kekejaman kolonialisme Belanda, pekabaran Injil telah menjadi batu sandungan besar bagi mereka yang akan datang pada Kristus. Apalagi ketika pekabaran Injil dijalankan dengan orientasi keuntungan politik dan ekonomi bagi pemerintahan penjajahan Belanda. Dalam hal ini, misi Protestan sebetulnya sedang melakukan tindakan bunuh diri. Hasil pengkonversian bukan petobat sejati tapi nominal Kristen seperti yang disebutkan di atas. Nominal Kristen bukan hanya menghasilkan sinkretisme tapi juga kemunafikan yang merupakan bahaya besar bagi kekristenan.

Dengan bergantung dan berafiliasi dengan kekuatan penjajah, misi Protestan tidak setia terhadap iman Kristen. Dengan menolak "indigenous theologising", misi Protestan telah mengingkari hakekat teologi itu sendiri. Teologi, seperti dikatakan T.B. Simatupang, seharusnya dimengerti "as the selfconscious reflective response to God's continuing action in

${ }^{18}$ T.B. Simatupang, "Christian Presence in War, Revolution and Development: The Indonesian Case", The Ecumenical Review 37, no. 1 (Januari 1985): 79. 
Christ in the midst of the concrete situation of the church's life, of man, and of society". ${ }^{19}$ Simatupang menjelaskan,

Though the faith is eternal, because it is faith in Him who is the same yesterday, today and tomorrow, nevertheless it should always be lived out, manifested and expressed in such a way that it remains Good News for the day and the hour. It should remain news; it should not give one the impression of reading a newspaper which is one year old, or even two hundred years old. ${ }^{20}$

Singkatnya, teologi seharusnya menjadi apa yang dikatakan Krüger sebagai "theologia in loco". ${ }^{21}$

Lebih dari itu, dengan mempopulerkan teologi pietis yang hanya menekankan cinta Tuhan melalui konversi spiritual dan mengabaikan keadilan, maka misi Protestan belum melaksanakan missio Dei (misi Allah) secara utuh. Dalam diri Tuhan, kasih dan keadilan tidak terpisahkan, seperti dikatakan Maz. 89:15: "Keadilan dan hukum adalah tumpuan takhtaMu, kasih dan kesetiaan berjalan di depanMu". Harvie M. Conn, Profesor Misi dari Westminster Theological Seminary mengingatkan kita bahwa penginjilan bukan hanya "preaching

${ }^{19}$ Simatupang, "Dynamics for Creative Maturity", 87.

${ }^{20}$ Simatupang, "Doing Theology in Indonesia Today", 20.

${ }^{21}$ Lihat Th. Müller Krüger, "Theologia in loco", dalam Basilea (Walter Freitag zum 60. Geburtstag) eds. Jan Hermelink dan Jochen Margull (Stuttgart: Evangelischer Missionsverlag, 1959), 313-25. Dikutip dari Simatupang, "Dynamics for Creative Maturity", 116. 
grace" tapi juga "doing justice". ${ }^{22}$ Menarik Simatupang mencatat bahwa pemimpin pemberontakan melawan kolonialisme Belanda di Saparua yang kemudian menjadi pahlawan nasional Indonesia, Thomas Matulessy yang dikenal sebagai Pattimura (1783-1817), ketika harus meninggalkan Saparua karena dikejar pasukan Belanda, ia meninggalkan Alkitab di mimbar gereja merujuk pada Mazmur 17, doa Daud dengan kalimat pembuka, "Dengarkanlah, Tuhan, perkara yang benar, perhatikanlah seruanku." ${ }^{23}$ Pesan ini ditujukan bukan hanya kepada tentara Belanda, tapi juga kepada gereja lokal yang menutup mata terhadap ketidakadilan.

Setelah VOC bangkrut 31 Desember 1799, pemerintah Belanda mengambil alih semua daerah VOC dan menjadikannya di bawah kekuasaan Pemerintah Hindia Belanda (the Dutch East Indies). ${ }^{24}$

\section{Pemerintah Hindia Belanda (1800-1942)}

Mirip VOC, Pemerintah Hindia Belanda yang mulai memerintah awal abad ke-19 juga menganut pola 'gereja negara'. Namun ada perbedaan mendasar antara pola VOC dan Hindia Belanda. Pada jaman VOC, seperti dijelaskan

\section{${ }^{22}$ Lihat Harvie M. Conn, Doing Justice and Preaching Grace}

(Phillipsburg: Presbyterian and Reformed Publishing Company, 1992).

${ }^{23}$ Simatupang, "Doing Theology in Indonesia Today", 23.

24 Th. van den End, "1800-2005: A National Overview. The Colonial Era: 1800-1900" dalam A History of Christianity in Indonesia, eds. Jan Sihar Aritonang dan Karel Steenbrink (Leiden and Boston: E.J. Brill, 2008), 137. 
sebelumnya, karena misi gereja negara dimasukkan dalam salah satu departemen VOC, maka gereja negara bergantung sepenuhnya dan berada di bawah cengkeraman kekuatan kolonialisme. Namun pada jaman Hindia Belanda, gereja negara lebih independen dan mandiri di dalam menjalankan misi Protestan. Melalui ketetapan Raja William I, Pemerintah Hindia Belanda menjadikan gereja negara dalam bentuk Gereja Protestan Hindia Belanda (the Protestant Church of the Netherlands Indies) di mana berbagai denominasi Protestan termasuk Lutheran masuk di dalamnya. Kemandirian Gereja Protestan terlihat dari keterbukaan dan kebebasannya mengundang berbagai lembaga misionari dari Eropa untuk membantu gereja lokal. ${ }^{25}$ Dari tahun 1800-1900, tercatat sekitar lima belas lembaga misionari melakukan misinya di Hindia Belanda. ${ }^{26}$

Independensi Gereja Protestan juga terlihat dari misinya memandirikan gereja etnis lokal dengan merintis apa yang Simatupang katakan sebagai "protochurches."27 Itu sebabnya, di penghujung abad ke-19, Gereja Protestan membuka diri terhadap 'indigenous theologising' dengan mengijinkan orang Kristen Indonesia terlibat dalam jabatan gerejawi sebagai "pembantu pendeta" atau "guru Injil", lalu sebagai "pendeta."28 Sekalipun orang Kristen Indonesia yang memiliki jabatan

\footnotetext{
${ }^{25}$ Titaley, "From Abandonment to Blessing", 75.

${ }^{26}$ Van den End, "The Colonial Era: 1800-1900", 141.

27 Simatupang, "Dynamics for Creative Maturity", 92.

${ }^{28}$ Prior and Hoekema, "Theological Thinking", 751.
} 
gerejawi tetap di bawah pimpinan misionari Eropa, ${ }^{29}$ kehadiran mereka-mereka ini yang disebut Simatupang sebagai "prototheological awareness," ${ }^{30}$ sangat penting bagi kemandirian gereja-gereja etnis lokal di Hindia Belanda. Sejarah mencatat kemandirian gereja etnis lokal terjadi pada abad ke-20 di mana Gereja Masehi Injili Minahasa berdiri tahun 1934 di Sulawesi Utara, Gereja Protestan Maluku tahun 1935 dan Gereja Masehi Injili Timor tahun 1947. Gereja-gereja etnis lainnya seperti gereja Tionghoa, gereja-gereja Jawa, Gereja Kalimantan Evangelis, dan Gereja Kristen Batak Protestan juga berdiri sekitar tahun-tahun tersebut. ${ }^{31}$

Karena didirikan pemerintah kolonial Hindia Belanda, maka independensi dan kemandirian Gereja Protestan terbatas. Sekalipun gereja Protestan menolak berbagai bantuan dari pemerintah kolonial untuk pekabaran Injil, namun semua biaya operasional Gereja Protestan menjadi tanggungan pemerintah kolonial. Hal tersebut menimbulkan keprihatinan bagi berbagai lembaga misionari. ${ }^{32}$ Sekalipun pemerintah kolonial tidak mencampuri misi pekabaran Injil, lembaga misionari khawatir misi dalam pelayanan sosial misalnya akan ditunggangi

${ }_{29}$ Orang Kristen Indonesia yang sudah meraih jabatan pendeta sekalipun, tidak bisa menjadi gembala sidang di gereja, paling tinggi menjadi asisten untuk misionaris Eropa. Simatupang, "Dynamics for Creative Maturity", 92.

30 Ibid.

31 Titaley, "From Abandonment to Blessing", 75.

32 Van den End, “The Colonial Era: 1800-1900”, 159. 
Pemerintah Hindia Belanda. Itu sebabnya lembaga misionari berinisiatif mendirikan berbagai pelayanan sosial seperti rumah sakit dan sekolah sekalipun kemudian nantinya dibantu oleh Gereja Protestan dan pemerintah kolonial. ${ }^{33}$ Lengketnya Gereja Protestan pada pemerintah kolonial menggambarkan situasi politik Belanda saat itu yang menyatukan gereja dan negara.

Hal lain yang membuat lembaga misionari prihatin terhadap Gereja Protestan yakni banyak hamba Tuhan dari Gereja Protestan menganut teologi liberal yang pada dasarnya mengabaikan pekerjaan misi. ${ }^{34}$ Munculnya risiko tersebut akibat komposisi elemen pendiri Gereja Protestan yang terdiri dari berbagai denominasi dan dipersatukan pemerintah kolonial, seperti yang disinggung di atas. Karena banyak hamba Tuhannya menganut teologi liberal, itu sebabnya mengapa paling sedikit selama abad sembilan belas Gereja Protestan pada dasarnya berfungsi sebagai "a government agency for the fulfilment of the religious needs of its Protestant subjects. As such, it was not supposed to do any missionary work." Th. van den End menambahkan, "Even if the government had allowed it to do so, the leadership of the church would not have felt an inner urge towards mission...."35 Dengan demikian, lembaga misionari yang paling banyak melakukan tugas pekabaran Injil dan mendirikan gereja.

33 Titaley, "From Abandonment to Blessing", 75.

34 Van den End, “The Colonial Era: 1800-1900”, 159.

35 Ibid., 138. 
Lembaga misi the German Rheinische Missionsgesellschaft, misalnya, merintis misi di Kalimantan Selatan (sejak 1835) dan Sumatera Utara (Tanah Batak, sejak 1862) dan mendirikan gereja di sana. ${ }^{36}$ Begitu pula dengan the Zending der Gereformeerde Kerken (ZGKN), lembaga misi dari the Dutch Reformed Church yang didirikan Abraham Kuyper, merintis misi dan mendirikan gereja di Sumba. ${ }^{37}$

Penting untuk dicatat, karena mengikuti pola pikir pemerintah kolonial, ketika menjalankan misi Protestan, mayoritas lembaga misionari Eropa memiliki pola pikir yang disebut van den End sebagai "the hard-core racism" yang beranggapan bahwa "other races simply unable to ascend to the level reached by Europeans, and would die out or forever remain in an inferior position." 38 Pola pikir tersebut bahkan dimiliki oleh Krüger, dekan pertama dari Hoogere Theologische School (HTS), ${ }^{39}$ yang berpendapat bahwa berbeda dengan orang Barat, pemikiran penduduk lokal Hindia Belanda tidak mampu menjadi "the foundation of clear, independent theological

36 Ibid., 141.

37 Th. van den End, "1800-2005: A National Overview. The Last Decades of the Colonial Era: 1900-1942" dalam A History of Christianity in Indonesia, eds. Jan Sihar Aritonang dan Karel Steenbrink (Leiden and Boston: E.J. Brill, 2008), 167.

38 Van den End, “The Colonial Era”, 145.

${ }^{39}$ HTS didirikan di Bogor tahun 1934 dan pindah 2 tahun kemudian ke Jakarta. Sekolahnya kemudian dikenal sebagai Sekolah Tinggi Teologia (STT) in 1954. Prior and Hoekema, "Theological Thinking", 757. 
thinking." ${ }^{40}$ Bahkan Hendrik Kraemer sendiri, misionari di Hindia Belanda dan tokoh misi dunia, beranggapan bahwa "western peoples had more talents in the field of the creative transfer of knowledge and science than...had the Javanese". ${ }^{41}$ Sehingga tidak heran jika kepemimpinan dan orang kunci di gereja-gereja di Hindia Belanda dan di HTS tetap dipegang misionari Eropa.

Menentang pandangan diskriminatif pemerintah kolonial dan para misionari yang menganggap penduduk lokal Hindia Belanda sebagai 'primitif', ketika memiliki kesempatan studi doktoral di Universitas Leiden, Belanda, Todoeng Soetan Goenoeng Moelia pada tahun 1933 menulis disertasinya tentang Het Primitieve Denken in de Moderne Wetenschap (Primitive Thinking within Modern Science). ${ }^{42}$ Dalam disertasi yang disupervisi Ph. Kohnstamm itu, Moelia yang kemudian menjabat Menteri Pendidikan Republik Indonesia dan mendirikan Universitas Kristen Indonesia, menolak pandangan antropolog L. Lévy-Bruhl yang menyatakan bahwa "the 'primitive' was somehow ontologically discontinuous with the 'modern'". 43 Bagi Moelia yang kemudian merintis penulisan

${ }^{40}$ Lihat Th. Müller Krüger, "Theologische Opleiding in Indie", De Opwekker 82 (1937): 317-334. Dikutip dari Prior and Hoekema, "Theological Thinking", 758.

${ }^{41}$ Ibid., 762.

${ }^{42}$ T.S.G. Moelia, Het Primitieve Denken in de Moderne Wetenschap (Groningen/Den Haag/Batavia: Wolters, 1933). Dikutip dari Klinken, Minorities, Modernity and the Emerging Nation, 262.

${ }^{43}$ Ibid., 70. 
Ensiklopedia Indonesia, pikiran primitif juga tahu tentang logika dan kasualitas serta mampu mencapai kesimpulan intelektual yang sama dengan manusia modern asalkan diberikan kesempatan belajar dan pengalaman untuk meningkatkan pengetahuan. ${ }^{44}$ Disertasi Moelia diterima baik di lingkaran akademik di Belanda. Kraemer mengulas disertasi Moelia di jurnal De Opwekker dan menggambarkannya sebagai "extraordinary". ${ }^{4}$

Pemikiran diskriminatif terhadap penduduk Hindia Belanda sangat mempengaruhi keberhasilan misi. Karena menganggap penduduk Hindia Belanda "lagging behind" dan kultur mereka "inferior, as is their religion," 46 ketika menjalankan misi Kristen, para misionari menyampaikannya dengan searah dan tidak mau mempelajari agama dan kultur dari mereka yang menerima Injil. Akibatnya, misi yang diemban bukan hanya tidak berhasil tapi juga membuat malu dan menjadi bahan tertawaan. ${ }^{47}$ Berbeda dengan yang dilakukan Albert C. Kruyt di Tanah Karo dan Pieter Middelkoop di Timor di mana sebelum menjalankan misi, mereka belajar agama dan kultur dari mereka yang akan diinjili. Tujuannya pertama-tama bukan untuk menghakimi tapi untuk mengenal agama dan kultur dari mereka yang diinjili. Melalui pengenalan ini, para misionaris dapat

\footnotetext{
44 Prior and Hoekema, "Theological Thinking", 762.

45 Simatupang, "Dynamics for Creative Maturity", 115.

46 Van den End, "The Colonial Era", 145.

47 Ibid., 148.
} 
memahami pemikiran mereka yang akan diinjili sehingga nantinya dapat menginjili dengan efektif. ${ }^{48}$ Melalui cara Kruyt dan Middelkoop tersebut, misi memiliki tingkat keberhasilan yang tinggi. ${ }^{49}$

Dengan demikian, kita menyimpulkan secara keseluruhan bahwa misi Protestan yang dijalankan pada jaman Hindia Belanda jauh lebih baik dibandingkan di jaman VOC. Sekalipun memiliki independensi dan kemandirian terbatas, dengan mengundang berbagai lembaga misi Eropa ke Hindia Belanda, Gereja Protestan telah turut berperan di dalam perintisan misi dan berdirinya gereja etnis melalui misi yang dijalankan lembaga misi tersebut. Kehadiran lembaga misi Eropa memainkan peran yang sangat strategis di dalam menjaga kemurnian misi Kristen bukan hanya dari kepentingan pemerintah kolonial tetapi juga dari teologi liberal yang kala itu mendominasi pemikiran sebagian besar hamba Tuhan Gereja Protestan.

Pengadopsian "the hard-core racism" oleh lembaga misi Eropa di Hindia Belanda tidak bisa lepas dari pemikiran jaman itu. Pada saat itu, bangsa Eropa merasa diri lebih superior dari bangsa yang ditaklukkan mereka. Kehadiran "the hard-core racism" menandakan lembaga misi telah dipengaruhi oleh kontemporer pemikiran Eropa pada saat itu. ${ }^{50}$ Memang Ernst

${ }^{48}$ Van den End, "The Last Decades of the Colonial Era," 172.

${ }^{49}$ Van den End, "The Colonial Era", 148.

${ }^{50}$ Ibid., 145. 
Troeltsch pernah menulis bahwa barangsiapa yang "dominates the world and is therefore dominated by the world". ${ }^{51}$ Namun Kristus mengingatkan kita akan kuat kuasa-Nya seperti dinyatakan dalam Yohanes 1:5: "Terang itu bercahaya di dalam kegelapan dan kegelapan itu tidak menguasainya."

Misi Kristen menuntut pemahaman agama dan kultur dari mereka yang menjadi target misi. Pentingnya pemahaman tersebut bukan hanya agar penginjilan menjadi efektif tapi juga untuk menghasilkan konversi sejati. Misi Protestan pada jaman Hindia Belanda percaya bahwa tanpa pertobatan dalam hati setiap individu Kristen, maka tidak mungkin terjadi konversi sejati. Lepas dari pekerjaan Roh Kudus, agar hati dikonversi, sangat penting bagi Injil dikomunikasikan dalam bahasa ibu dari mereka yang diinjili. ${ }^{52}$ Dengan kata lain, tanpa menerjemahkan berita Injil, maka konversi sejati tidak akan mungkin terjadi. Dan tanpa pemahaman agama dan kultur dari mereka yang diinjili, proses penerjemahan tidak mungkin terwujud. Lamin Sanneh, D. Willis James Professor of Missions and World Christianity di Yale Divinity School, mengkonfirmasi hal ini dalam bukunya Translating the Message..$^{53}$

${ }^{51}$ Ernst Troeltsch, The Social Teachings of the Christian Churches, vol. 1 (New York: Harper \& Row, 1960), 345.

52 Van den End, “The Colonial Era”, 147.

${ }^{53}$ Lihat Lamin Sanneh, Translating the Message: The Missionary Impact on Culture (Maryknoll: Orbis Books, 2009). 
Pemerintah Hindia Belanda berakhir dan dilanjutkan dengan penjajahan Jepang tahun 1942 yang mengkampanyekan kesejahteraan Asia Timur. ${ }^{54}$

\section{PENJAJAHAN JEPANG (1942-1945)}

Penjajahan Jepang selama 3 tahun telah menjadi berkat terselubung (blessing in disguise) bagi perkembangan gerejagereja di Indonesia. Karena memiliki agenda untuk mewujudkan "the Greater Asia Co-prosperity Sphere," 55 setelah mengusir kolonialisme Belanda, pemerintah penjajahan Jepang mengganti kepemimpinan gereja dari misionari Eropa ke pendeta lokal. Simon Marantika, misalnya, dipilih menjadi Ketua Sinode Gereja Protestan Maluku pada tahun 1942.56 Perubahan kepemimpinan ke orang lokal membuat kekristenan sadar akan tanggung jawab iman yang diembannya. ${ }^{57}$ Dengan kata lain, di bawah penjajahan Jepang, gereja-gereja Indonesia mengalami "moratorium" dalam arti bahwa semua bantuan dan kontak antara gereja-gereja dengan lembaga misi mereka terputus total. ${ }^{58} \mathrm{Hal}$ ini tidak mudah bagi gereja tapi menjadi

54 Titaley, "From Abandonment to Blessing", 76.

55 Th. van den End, “1800-2005: A National Overview. Indonesian Christianity during the Japanese Occupation, 1942-1945" dalam A History of Christianity in Indonesia, eds. Jan Sihar Aritonang dan Karel Steenbrink (Leiden and Boston: E.J. Brill, 2008), 179.

${ }^{56}$ Ibid., 182.

57 Titaley, "From Abandonment to Blessing", 76.

58 Simatupang, "Christian Presence in War, Revolution and Development", 81 . 
berkat tersendiri bagi gereja karena gereja dilatih spirit perjuangannya untuk bisa mandiri nantinya.

Selama penjajahan Jepang, para hamba Tuhan Jepang (Japanese ministers) memainkan peran penting dalam keberlanjutan misi Kristen di Indonesia. Gereja dan lembaga misi Kristen di Jepang mengirimkan misionari beberapa kali untuk membantu gereja-gereja. Tersebar di beberapa daerah, a.l., Kalimantan, Sulawesi Utara, Sulawesi Selatan, dan Maluku, hamba Tuhan Jepang bertugas bukan hanya "provided funds" dan "ordained Indonesians as ministers," tetapi juga "organised courses for church workers" dan "visited the congregations." ${ }^{59}$ Dengan dukungan dari hamba Tuhan Jepang, gereja mencoba sebisa mungkin untuk bertahan tanpa dukungan Eropa. Di beberapa tempat ketika terjadi transisi pengambilalihan kekuasaan dari Belanda ke Jepang, Muslim memanfaatkan situasi untuk mengintimidasi dan bahkan menganiaya orang Kristen. Pada saat itu, sejumlah orang Kristen Indonesia dan misionari Eropa dibunuh. ${ }^{60}$ Kehadiran hamba Tuhan Jepang juga untuk melindungi dan mengakhiri penganiayaan oleh Muslim seperti yang dilakukan Pdt. Shusho Miyahira di Makassar, Sulawesi Selatan. ${ }^{61}$

Di sini kita menyimpulkan bahwa pemeliharaan Allah begitu besar terhadap gereja-gereja Indonesia. Siapa

${ }^{59}$ Van den End, "Indonesian Christianity during the Japanese Occupation", 184.

${ }^{60}$ Ibid., $179-80$.

${ }^{61}$ Ibid., 184. 
menyangka kekristenan yang pernah dilarang di Jepang dan minoritas pada tahun 1940 berjumlah hanya sekitar setengah juta, ${ }^{62}$ memiliki solidaritas begitu besar terhadap gereja-gereja Indonesia. Bersolidaritas sebagai sesama tubuh Kristus menuntut pengorbanan. Van den End mencatat bahwa gereja dan lembaga misi Jepang pernah mengirimkan 10 hamba Tuhan dan hanya 6 orang tiba dengan selamat pada Januari 1944 setelah kapal mereka ditorpedo kapal perang Amerika. Namun hal ini tidak menciutkan hati mereka. Di tahun yang sama, 9 hamba Tuhan Jepang dikirim ke Indonesia. ${ }^{63}$

Berbagai tantangan tersebut mempersiapkan gereja-gereja Indonesia menuju kemandirian, menjadi apa yang Simatupang katakan sebagai "protochurches." 64 Simatupang menulis,

With the Japanese occupation, the Western dominance over Indonesia came to an end. But the church in the meantime had become strongly rooted in the nation. Historically, the church in Indonesia was planted and matured under the umbrella of Western expansion. During the Japanese occupation the churches proved able to continue their existence after that historical external umbrella was removed. In a way, the Japanese occupation prepared the churches for the next period, the period of national independence, by infusing into the minds of the leaders of the churches the hard lesson that being the

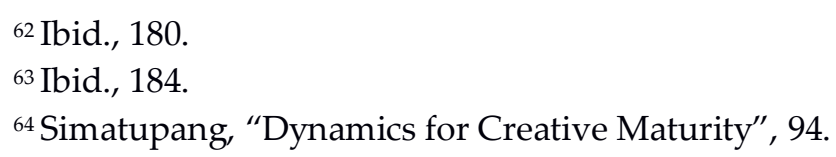


church means living under God in the midst of the realities of the day without any ties, if necessarym with churches outside the country. ${ }^{65}$

Setelah Jepang dikalahkan dan perang dunia kedua berakhir, gereja-gereja Indonesia kembali melakukan kontak dengan lembaga misi Eropa. Tapi kali ini mereka tidak lagi memperlakukan misionari Eropa sebagai tuan tapi setara. Kesadaran menjadi gereja yang mandiri mencapai puncaknya pada proklamasi kemerdekaan Indonesia tahun 1945.

\section{KEMERDEKAAN INDONESIA (1945-1998)}

Gereja Protestan dalam periode ini berubah drastis: tidak lagi bergantung pada misi luar negeri tetapi menjadi independen dan mandiri serta memiliki profil nasional. Pergumulan utama gereja-gereja Protestan dalam jaman kemerdekaan adalah bagaimana terlibat dalam gerakan nasional. Berbeda dari gereja-gereja Katolik yang mengambil bagian dalam gerakan nasionalis dengan hampir tanpa halangan, gereja-gereja Protestan harus menghadapi tantangan besar. Bagaimana caranya agar gereja-gereja Protestan yang pada dasarnya merupakan gereja etnis seperti Gereja Protestan Maluku dan Gereja Batak Kristen Protestan menjadi gereja Indonesia yang melihat "the whole of Indonesia" sebagai "one field for the common calling of all churches to witness and

${ }^{65}$ Ibid., 99. 
service"? ${ }^{66}$ Pada Mei 1950, para pemimpin gereja memutuskan untuk mendirikan the Indonesian Council of Churches (Dewan Gereja-Gereja di Indonesia, DGI) dengan tujuan mendirikan Gereja Kristen yang Esa di Indonesia. "[N]ational consciousness," menurut Simatupang, adalah salah satu drive untuk mendirikan DGI, "in the sense that the ethnic churches were seen as being called to grow into one church in order to express together the Christian presence in the nation." 67

Sejarah mencatat Gereja Protestan memainkan peran strategis di dalam mewujudkan Indonesia yang satu. Sidang Badan Penyelidik Usaha Persiapan Kemerdekaan Indonesia (BPUPKI) pada 29 Mei hingga 1 Juni 1945 yang membahas tentang dasar negara (Weltanschauung) Indonesia menemui jalan buntu akibat konfrontasi ideologi antara golongan Islam yang menghendaki Islam dasar negara dan golongan kebangsaan yang menginginkan Indonesia negara sekuler di mana negara dan agama terpisah. Pidato Soekarno 1 Juni 1945 tentang Pancasila berhasil mencairkan kebuntuan dan diterima kedua pihak.

Namun Pancasila kemudian dirumuskan kembali 22 Juni 1945 dalam dokumen yang dikenal sebagai Piagam Jakarta. Dalam dokumen tersebut, sila pertama Pancasila, "Ketuhanan yang Maha Esa" direformulasikan dengan menambahkan frasa: "Ketuhanan, dengan kewajiban menjalankan syariat Islam bagi

66 Ibid., 108.

${ }^{67}$ Simatupang, "Doing Theology in Indonesia Today", 25. 
pemeluk-pemeluknya," yang dikenal sebagai '7 kata.' Sekalipun sudah ditegaskan bahwa penambahan 7 kata hanya diperuntukkan bagi Muslim, bukan untuk non-Muslim, penambahan 7 kata tersebut langsung mendapatkan berbagai perlawanan, khususnya dari pihak Kristen. Latuharhary, tokoh Protestan dan anggota BPUPKI, menyatakan keberatannya dengan mengatakan bahwa 7 kata tersebut "could have considerable consequences regarding other religions, and moreover could lead to difficulties in connection with the adatistiadat (customary law)." 68 Setuju dengan Latuharhary, tokoh kebangsaan lainnya seperti Wongsonegoro dan Hoesein Djajadiningrat juga menentang 7 kata, yang bagi mereka 7 kata tersebut "may well create fanaticism, because it seems that Muslims would be forced to keep shari'ah." 69

Tanggal 18 Agustus 1945, sehari setelah Proklamasi Kemerdekaan, dalam pertemuan pertama Panitia Persiapan Kemerdekaan Indonesia (PPKI), ${ }^{70}$ Piagam Jakarta dibatalkan. Ketika PPKI memulai pertemuannya, Muhammad Hatta, yang kemudian menjadi Wakil Presiden Republik Indonesia yang pertama, mengusulkan perubahan draf dari Pembukaan (preamble) Konstitusi. Hatta yang mendapatkan informasi dari

${ }^{68}$ B.J. Boland, The Struggle of Islam in Modern Indonesia (The Hague: Martinus Nijhoff, 1971), 28.

${ }^{69}$ Ibid., 29.

70 PPKI didirikan pada 7 Augustus 1945 untuk menggantikan BPUPKI dan dipimpin Sukarno sebagai Ketua dan Muhammad Hatta sebagai Wakil Ketua. 
pejabat Angkatan Laut Jepang bahwa di mata kekristenan, 7 kata mendiskriminasikan kelompok agama minoritas karena kehadirannya hanya akan melayani sebagian penduduk bangsa Indonesia. ${ }^{71}$ Jika 7 kata tersebut tidak dicabut, maka kekristenan yang mendominasi wilayah Timur Indonesia akan memisahkan diri. Meresponi hal tersebut, pertemuan PPKI merekomendasikan pencabutan 7 kata dari Pembukaan Konstitusi.

Dengan demikian, kita dapat menyimpulkan bahwa misi gereja-gereja Protestan untuk berangkat dari gereja etnis menjadi 'gereja Indonesia' berjalan secara terpadu dengan misi gereja menggagalkan Piagam Gereja untuk mewujudkan Indonesia yang satu. Dengan kata lain, misi gereja tidak hanya sebatas memperhatikan dirinya sendiri tapi bagaimana menjadi berkat bagi rakyat banyak.

Setelah kemerdekaan Indonesia, Sukarno menjadi presiden Indonesia yang pertama, di mana pemerintahannya dikenal dengan istilah Orde Lama.

\section{Orde Lama (1945-1966)}

Tantangan gereja-gereja Protestan dalam pemerintahan Sukarno masih seputar Piagam Jakarta. Untuk mengkompensasi Muslim dengan dihapusnya Piagam Jakarta, 3 Januari 1946, Pemerintah Orde Baru mendirikan Kementerian

${ }^{71}$ Deliar Noer, Partai Islam di Pentas nasional, 1945-1965 (Jakarta: Pustaka Utama Grafiti, 1987), 40. 
Agama sekalipun dengan berbagai kritikan terhadapnya. Latuharhary menegaskan bahwa kementerian ini "might give rise to feelings of offence and dislike and he suggested that religious affairs be handled by the Ministry of Education." 72 Kritikan tajam juga datangnya dari J.W.M. Bakker, S.J. dari pihak Katolik, bahwa Kementerian Agama dari semula telah terbukti menjadi "a bulwark of Islam and an outpost for an Islamic State."73

Kehadiran kementerian ini semula hanya untuk melayani kaum Muslim. Sekalipun kemudian diperluas pelayanan ke non-Muslim-Protestan, Katolik, dan Hindu-Buddha, kehadirannya, menurut Clifford Geertz, "is for all intents and purposes a santri [devouted Islam] affair from top to bottom." ${ }^{74}$

Kementerian Agama telah dipakai oleh santri Muslim untuk mempropagandakan agenda mereka. Berupaya mendorong abangan Muslim untuk berkomitmen terhadap Islam, santri mendorong kementerian mengeluarkan larangan terhadap kebatinan yang merupakan agama abangan. Tahun 1952, kementerian menetapkan bahwa setiap agama paling

72 Jan S. Aritonang, “1800-2005: A National Overview. Independent Indonesia (1945-2005)" dalam A History of Christianity in Indonesia, eds. Jan Sihar Aritonang dan Karel Steenbrink (Leiden and Boston: E.J. Brill, 2008), 190 .

${ }^{73}$ J.W.M. Bakker, "De Godsdienstvrijheid in De Indonesische Grondwetten," Het Missiewerk no.4 (1956): 215. Dikutip dari Boland, The Struggle of Islam, 106.

${ }^{74}$ Clifford Geertz, The Religion of Java (Chicago: The University of Chicago Press, 1976), 200. 
sedikit harus memiliki "a prophet, a holy book, and international recognition." Upaya ini tidak berhasil karena mendapatkan perlawanan dari Hindu Bali. ${ }^{75}$ Tahun 1961, kembali menetapkan definisi agama dengan tujuan menyangkali keberadaan kebatinan. Agama, menurut Kementerian Agama, meliputi: "a holy scripture, a prophet, the absolute lordship of Tuhan Yang Maha Esa (God), and a system of law for its followers." ${ }^{76}$ Berdasarkan definisi agama tersebut, untuk alasan politis, Sukarno kemudian mengeluarkan Ketetapan Presiden no.1/1965 yang, antara lain, menetapkan 6 agama negara, yakni Islam, Protestan, Katolik, Hindu, Buddha, dan Konfusianisme. ${ }^{77}$

Perjuangan kekristenan menolak Piagam Jakarta dan Kementerian Agama karena kedua produk hukum tersebut bersifat diskriminatif. Namun kekristenan bersikap diam ketika Kementerian Agama mendefinisikan agama yang menyebabkan Presiden Sukarno menetapkan enam agama resmi negara termasuk Protestan. Sikap kekristenan yang tidak konsisten dan ambigu ini disebabkan karena kekristenan turut menikmati posisinya sebagai salah satu agama negara di samping sebagian besar mayoritas sudah terakomodir kepentingannya. Apapun alasannya, kekristenan seharusnya

${ }^{75}$ Niels Mulder, Mysticism and Everyday Life in Contemporary Java:

Cultural Persistence and Change (Singapore: Singapore University Press, 1978), 4.

${ }^{76}$ Ibid., 6.

77 Ibid. 
mengeritik pendefinisian agama oleh Kementerian Agama karena kebijakan tersebut bersifat diskriminatif dan memberi peluang campur tangan negara dalam kehidupan internal agama.

Selanjutnya kita akan melihat apakah sikap kekristenan yang tidak konsisten dan ambigu ini berlanjut ke pemerintahan berikutnya, yakni pemerintahan Orde Baru Soeharto.

\section{Orde Baru (1966-1998)}

Setelah Soeharto didukung berbagai elemen bangsa menghancurkan kudeta tahun 1965, yang dikenal sebagai G-30S/PKI atau Gestapu/PKI, maka terjadilah pergantian pemerintahan dari Sukarno ke Soeharto. Setelah pemberontakan PKI yang gagal itu, dengan didukung tentara, NU dan Muhammadiyah terlibat aktif dalam gerakan pembalasan anti-komunis. ${ }^{78}$ Kelompok-kelompok pemuda mereka berpindah dari desa ke desa, menangkapi dan mengeksekusi orang-orang yang diduga komunis. Bagi sebagian besar mereka, perlawanan terhadap orang-orang komunis bisa dianggap "an aspect of the djihäd, the "Holy War" against the enemies of Islam, God's foes."79 Akibatnya, dalam hitungan bulan, sedikitnya setengah juta komunis terbunuh,

${ }^{78}$ Greg Barton, "Islam and Politics in the New Indonesia" dalam Islam in Asia: Changing Political Realities, eds., Jason F. Isaacson dan Colin Rubenstein (New Brunswick and London: Transaction Publishers, 2002), 8.

${ }^{79}$ Boland, The Struggle of Islam, 145. 
dan ratusan ribu orang dipenjara dan disiksa. ${ }^{80}$ Sebagian besar dari para korban ini adalah orang-orang komunis Islam abangan.

Di dalam situasi yang sangat berbahaya ini, sangatlah penting bagi setiap orang berafiliasi dengan agama negara; jika tidak, akan dituduh komunis. Dengan dikeluarkannya Ketetapan Presiden no. 1/1965, apa yang dimaksud dengan "agama" di dalam pasal 29 Undang-Undang Dasar 1945 harus ditafsirkan sebagai Muslim, Protestan, Katolik, Hindu, Buddha, dan Konfusianisme. Tetapi, karena keterlibatan komunis China di dalam pemberontakan PKI yang gagal tersebut, maka di dalam Keputusan MPRS no. XXVII pada tahun 1966, Konfusianisme tidak lagi disebut karena dianggap sebagai agama dan kepercayaan China. Perlu dicatat bahwa di dalam mencari perlindungan, banyak kaum Muslim abangan, yang mendukung organisasi front yang berafiliasi dengan PKI, tidak kembali berkomitmen ke agama Islam. "The slaughter of the suspected 'communist' abangan in 1965-1966, and the pressure to show that one had become an obedient Muslim," seperti dikatakan Niels Mulder, "boomeranged on Islam." 81 Sebaliknya, mereka beralih ke Protestan atau Katolik, dan bahkan ke agama Hindu. Pada awal tahun 1969, Dewan Gereja-

${ }^{80}$ Benedict R. O'G. Anderson, Language and Power: Exploring Political Cultures in Indonesia (Ithaca and London: Cornell University Press, 1990), 6.

${ }^{81}$ Mulder, Mysticism and Everyday Life, 6. 
gereja Dunia (WCC) melaporkan bahwa dari tahun 1965 hingga 1968, 2,5 juta Muslim abangan berlalih ke agama Kristen. ${ }^{82}$

Pergumulan gereja-gereja Protestan di awal pemerintahan Orde Baru berorientasi pada konsekuensi berpindahnya abangan Muslim menjadi Kristen. Meresponi akan perpindahan agama tersebut, Muslim mendesak pemerintah menyelenggarakan Musyawarah Antar Umat Beragama antara pemimpin-pemimpin Muslim dan Kristen dengan Menteri Agama sebagai moderator. Membela kelompok Islam, konsultasi itu, yang diadakan pada 30 November, 1967, bertujuan mengeluarkan pernyataan bersama yang menyatakan bahwa: (1) Setiap kelompok religius harus membatasi kegiatankegiatan religiusnya pada lingkungannya sendiri; dan (2) Tidak boleh ada kelompok religius yang mencoba untuk mengubah seseorang yang sudah mempunyai agama untuk berpindah agama.

Baik Dewan Gereja-gereja di Indonesia (DGI) maupun Majelis Agung Wali Gereja Indonesia (MAWI) menolak menandatangani pernyataan bersama tersebut, karena larangan perpindahan agama bagi mereka yang sudah beragama, seperti ditegaskan T.B. Simatupang yang mewakili DGI, bertentangan dengan perintah Alkitab untuk menyebarkan Injil ke seluruh umat

${ }^{82}$ Angkatan Baru, January 23, 1969. Dikutip dari Allan Arnold Samson, "Islam and Politics in Indonesia" (Ph.D. diss., University of California at Berkeley, 1972), 237. 
manusia (Mark.15:16). ${ }^{83}$ Sekalipun demikian, mereka setuju ketika menjalankan misi harus menjauhkan "all kinds of improper methods of propaganda such as persuading, seducing, forcing and offering gifts." 84 Dialog pada akhirnya berakhir tanpa menghasilkan pernyataan yang melarang perpindahan agama kepada mereka yang telah beragama. ${ }^{85}$

Respon Muslim terhadap kasus ini tidak berhenti di sini. Karena banyaknya abangan Islam masuk agama Kristen, mereka kemudian mendesak pemerintah membatasi pendirian rumah ibadah. Pada tanggal 13 September 1969, Menteri Agama dan Menteri Dalam Negeri mengeluarkan Surat Keputusan Bersama (SKB) Menag dan Mendagri No.01/BER/MDNMAG/1969 yang mengatur pendirian rumah ibadah dengan tujuan tidak saja menjamin kebebasan beragama, tetapi juga menjaga stabilitas dan kesatuan nasional. Di dalam penerapannya, SKB tersebut mensyaratkan setiap rumah ibadah harus memperoleh ijin dari kepala pemerintah setempat (artikel 1), dan ijin dari pemerintah harus memperoleh persetujuan dari wakil organisasi keagamaan dan pemimpin agama setempat (artikel 3). ${ }^{86}$ Meskipun keputusan tersebut diterapkan kepada semua kelompok religius, dalam

${ }^{83}$ T.B. Simatupang, The Fallacy of a Myth (Jakarta: Pustaka Sinar Harapan, 1995), 199.

${ }^{84}$ Aritonang, “Independent Indonesia (1945-2005)," 208.

${ }^{85}$ Simatupang, The Fallacy of a Myth, 199-200.

${ }^{86}$ Weinata Sairin, ed., Himpunan Peraturan di bidang Keagamaan (Jakarta: BPK Gunung Mulia, 1996), 3-6. 
kenyataannya, keputusan tersebut hanya diperuntukkan untuk mengatur tempat-tempat ibadah bagi kelompok non-Muslim, khususnya bagi orang-orang Kristen. Dengan adanya persyaratan tersebut, khususnya artikel 3, maka akan sangat sulit bahkan tidak mungkin bagi non-Muslim, khususnya orang-orang Kristen, untuk membangun rumah ibadah mereka di dalam sebuah komunitas di mana orang-orang Muslim adalah mayoritas.

Sejak tahun 1965, pertumbuhan dan perkembangan kekristenan luar biasa besarnya khususnya dalam hal peningkatan jumlah. Selain peran dari Indonesian evangelists seperti Petrus Octavianus, Stephen Tong dan Christ Marantika, pada saat itu banyak agen misi dari luar negeri, khususnya dari kalangan Injili dan Pentakosta, yang melakukan kegiatan misinya di Indonesia. ${ }^{87}$ Mengetahui laju pertumbuhan gereja yang begitu pesat, Muslim kembali mendesak Kementerian Agama mengeluarkan Keputusan Menteri no.70/1978 tentang "Bantuan Asing bagi Lembaga-lembaga Agama di Indonesia." Dalam penerapannya, keputusan ini melarang para misionaris asing untuk datang ke Indonesia (Pasal 3, bagian 1). Setiap bantuan asing dalam bentuk para pekerja, material, atau keuangan, hanya bisa dilaksanakan setelah memperoleh persetujuan dari dan melewati Menteri Agama (Pasal 2). ${ }^{88}$

${ }^{87}$ Aritonang, “Independent Indonesia (1945-2005)," 203, 208.

${ }^{88}$ Ibid., 204-5. 
Meresponi keputusan menteri tersebut, DGI dan MAWI mempertanyakan mengapa, jika Kementerian Agama dimaksudkan untuk melayani semua agama, kementerian itu tidak membahas keputusan itu dengan semua kelompok agama sebelum diputuskan. Sebagai jawaban terhadap keputusan itu, kedua organisasi agama ini mengajukan keberatan kepada Menteri, Wakil Presiden Adam Malik, dan bahkan kepada Presiden Soeharto, meminta agar peraturan-peraturan tersebut ditinjau kembali. Alasan utama mereka adalah bahwa peraturan-peraturan tersebut bertentangan dengan Pasal 29 Undang-Undang Dasar, yang menjamin kebebasan beragama. Selain itu, Pasal 29 Undang-Undang Dasar harus dijabarkan oleh lembaga legislatif bekerja sama dengan eksekutif, yaitu Dewan Perwakilan Rakyat (DPR) dan Presiden, bukan oleh Peraturan Menteri di bawah Presiden. Berdasarkan pertimbangan-pertimbangan ini, peraturan-peraturan tersebut oleh karenanya, menurut pendapat mereka, tidak memiliki dasar hukum sama sekali. ${ }^{89}$ Harian Sinar Harapan, yang dipandang memberikan suara kepada orang-orang Kristen, mengungkapkan pandangan Kristen di dalam sebuah editorial:

We do not have to become an expert on the comparative study of religion in order to know that every major religion cannot accept becoming a religion which is not universal...This means

${ }^{89}$ Ramlan Surbakti, "Interrelation between Religious and Political Power under New Order Indonesia” (Ph.D. diss., Northern Illinois University, 1991), 153. 
that the freedom of propagating religion to all persons is the intrinsic part of the universality of religion..$^{90}$

Meresponi keprihatinan DGI dan MAWI, pemerintah kemudian mengeluarkan Keputusan Bersama antara Menteri Agama dan Menteri Dalam Negeri no. 1/1979 yang menguatkan Keputusan Menteri no. 70/1978 tetapi tanpa bagian (a) Pasal 2 dan mengurangi Keputusan Menteri no. 77/1978. ${ }^{91}$

Dengan demikian, ada beberapa kesimpulan yang bisa kita ambil. Pertama, gereja-gereja telah melakukan tindakan yang tepat dengan meng-welcome masuknya abangan Muslim ke Kristen. Hal ini merupakan berkat tersendiri bagi gerejagereja, sekalipun ada harga yang harus dibayar untuk menghadapi manuver Muslim karena perpindahan agama tersebut. Namun di sisi lain, gereja-gereja harus waspada dengan perpindahan agama tersebut dengan bertanya, apakah tindakan yang diambil abangan Muslim itu sesuatu yang sejati (genuine) ataukah hanya sekadar mencari perlindungan dari gereja dan sejauh 'asal bukan Islam.' Menarik ketika membahas masuknya abangan Islam menjadi Kristen, Avery T. Willis dalam bukunya Indonesian Revival: Why Two Millions came to Christ yang diterbitkan oleh William Carey Library menyebutkan tiga faktor utama penyebab konversi abangan

${ }^{90}$ Ibid., 354. Dikutip dari Sinar Harapan, 1978.

${ }^{91}$ Lihat Sairin, ed., Himpunan Peraturan, 63-68. 
Islam: "spiritual need, government and protection."92 Singkatnya, gereja harus mencermati motivasi di balik konversi. Jika ada motivasi lain selain kebutuhan spiritual, maka konversi menjadi tidak sejati akibatnya muncul sinkretisme dan kemunafikan yang menjadi musuh agamaagama.

Kedua, sekalipun gereja-gereja tidak berkompromi untuk menaati panggilan ilahi untuk memberitakan Injil kepada setiap makhluk, seperti dijelaskan di atas, mereka menolak "all kinds of improper methods of propaganda such as persuading, seducing, forcing and offering gifts." Hal ini penting untuk menjaga kesejatian dalam konversi. Namun perlu digarisbawahi, penginjilan yang disertai aksi sosial tidak termasuk dalam kategori 'improper methods' di atas. Penting untuk dicatat bahwa menurut Lausanne Conference 1974, penginjilan tidak bisa dilepaskan daripada aksi sosial. Konferensi tersebut merumuskan tiga macam hubungan antara penginjilan dan aksi sosial. Hubungan pertama, aksi sosial (social action) dipandang sebagai "a means to evangelism." Dalam hal ini, "evangelism and the winning of converts," seperti dikatakan John Stott, "are the primary ends in view, but social action is a useful preliminary, an effective means to these ends." ${ }^{93}$ Sisi negatif dari metode ini yakni dapat dengan mudah

${ }^{92}$ Avery T. Willis, Indonesian Revival: Why Two Millions came to Christ (Pasadena: William Carey Library, 1977), 12.

${ }^{93}$ John Stott, Christian Mission in the Modern World (Downers Grove: InterVarsity Press, 2008), 41. 
menimbulkan kemunafikan dan memunculkan istilah "rice Christians" dan "rice evangelists." 94

Hubungan kedua, aksi sosial berfungsi sebagai "a manifestation of evangelism." Dalam hal ini, "social action," menurut Stott, "becomes the 'sacrament' of evangelism, for it makes the message significantly visible." ${ }^{\prime 5}$ J. Herman Bavinck, dalam bukunya An Introduction to the Science of Missions, setuju dengan pendekatan ini. Medis dan pendidikan, menurut Bavinck, adalah lebih dari "a legitimate and necessary means of creating an opportunity for preaching" karena "if these services are motivated by the proper love and compassion, then they cease to be simply preparation, and at that very moment become preaching." ${ }^{\prime 96}$ Seperti dikatakan Yesus dalam Yohanes 14:11, "Percayalah kepadaKu, bahwa Aku di dalam Bapa dan Bapa di dalam $\mathrm{Aku}$; atau setidak-tidaknya, percayalah karena pekerjaan-pekerjaan itu sendiri."

Hubungan ketiga, ketika aksi sosial menjadi "a partner of evangelism." Stott menjelaskan pendekatan ini,

As partners the two belong to each other and yet are independent of each other. Each stands on its own feet in its own right alongside the other. Neither is a means to the other, or even a manifestation of the other. For each is an end in itself.

94 Ibid.

95 Ibid., 42.

${ }^{96} \mathrm{~J}$. Herman Bavinck, An Introduction to the Science of Missions

(Phillipsburg: Presbyterian and Reformed Publishing Company, 1992), 113. 
Both are expressions of unfeigned love. As the National Evangelical Anglican Congress at Keele put it in 1967, 'Evangelism and compassionate service belong together in the mission of God' (para. 2.20). ${ }^{97}$

Sekalipun penginjilan dan aksi sosial memiliki hubungan independen satu terhadap yang lain, keduanya memiliki hubungan yang erat yakni sama-sama merupakan bagian dari misi Allah. Bagian Firman Tuhan yang mendukung pandangan ini, a.1., 1 Yohanes 3:17-18, "Barangsiapa mempunyai harta duniawi dan melihat saudaranya menderita kekurangan tetapi menutup pintu hatinya terhadap saudaranya itu, bagaimanakah kasih Allah dapat tetap di dalam dirinya? Anakanakku, merilah kita mengasihi bukan dengan perkataan atau dengan lidah, tetapi dengan perbuatan dan dalam kebenaran," dan Matius 5:45, "Karena dengan demikianlah kamu menjadi anak-anak Bapamu yang di sorga, yang menerbitkan matahari bagi orang yang jahat dan orang yang baik dan menurunkan hujan bagi orang yang benar dan orang yang tidak benar."

Ketika harus memilih satu di antara ketiga opsi ini, kaum Injili terpecah. Leighton Ford, misalnya, cenderung memilih opsi (i), J. Herman Bavinck opsi (ii), sedangkan John Stott condong pada opsi (iii). ${ }^{98}$ Di manakah posisi gereja-gereja di Indonesia? Bagi penulis, gereja-gereja seharusnya tidak

${ }^{97}$ Stott, Christian Mission, 43.

${ }^{98}$ Lihat Ibid., 25-28. 
memilih salah satu dari ketiga opsi tersebut. Ketiga opsi tersebut bukan untuk dipilih, tapi untuk dimanfaatkan, dengan urutan: (i), (ii), (iii). Artinya, aksi sosial pertama-tama berfungsi sebagai "alat" penginjilan. Jika hal itu gagal, aksi sosial menjadi "manifestasi" penginjilan. Tapi jika hal itu tidak berhasil juga, maka aksi sosial harus berfungsi sebagai "partner" penginjilan. Artinya aksi sosial dilakukan dengan tanpa embel-embel penginjilan.

\section{KONKLUSI}

Kehadiran gereja-gereja Protestan di Indonesia merupakan anugerah Tuhan semata. Ketika misi Protestan pada masa VOC dan Gereja Protestan tidak dapat berbuat banyak dalam pekabaran Injil karena berada di bawah kendali pemerintahan kolonial Belanda, maka Tuhan memimpin lembaga misi Eropa menjalankan tugas pekabaran Injil di seluruh Nusantara. Melalui penjajahan Jepang dan kemerdekaan Indonesia, gereja-gereja Protestan belajar menjadi 'gereja Indonesia' (protochurches) yang mandiri dan sekaligus melepaskan kebergantungan terhadap lembaga misi Eropa dan pemerintah kolonialisme Belanda. Kemandirian merupakan momen yang indah bagi gereja-gereja untuk belajar bersandar sepenuhnya kepada Kristus, Sang Kepala Gereja yang telah menebus gereja dengan darah-Nya.

Kehadiran gereja-gereja Protestan di bumi persada Nusantara untuk membawa misi Tuhan yang mencakup Mandat Injili dan Mandat Budaya. Hanya anugerah Tuhan semata, gereja-gereja dapat tetap menjalankan Mandat Injili di 
negara yang memiliki penduduk Muslim terbanyak di seluruh dunia. Karena campur tangan Tuhan, melalui penolakan terhadap Piagam Jakarta, kekristenan telah memainkan peran strategis di dalam mencegah perpecahan bangsa dan mewujudkan Indonesia yang satu.

Menjalankan misi Tuhan akan mendatangkan banyak musuh. Orang Kristen yang hidup dengan konsisten sesuai dengan ajaran Firman Tuhan dan tidak berkompromi dengan dosa, pasti punya banyak musuh. Dalam Matius 5:44, ketika berkata "kasihilah musuhmu," Yesus mengasumsikan semua orang Kristen punya musuh. Yesus tidak mengatakan 'jika engkau punya masuh kasihilah dia,' perkataan-Nya jelas, "kasihilah musuhmu." Kata "musuhmu" di sini dalam bahasa aslinya menggunakan objective-genitive dan bukan subjectivegenitive. Artinya musuh kita bukan seseorang yang kita benci tapi seseorang yang membenci kita. Kita di sini adalah obyek dari musuh kita, bukannya subyek.

Itu sebabnya mengapa ketika menjalankan kehendak Tuhan, gereja-gereja tidak dapat melepaskan dirinya dari berbagai tantangan dan penderitaan. Yesus mengutus orang Kristen dalam dunia seperti "domba ke tengah-tengah serigala" (Mat.10:16). Untuk menjadi pengikut Yesus memang tidak gampang. Gereja-gereja harus "menyangkal dirinya, memikul salibnya" (Mat.16:24). Namun demikian, gereja-gereja jangan berkecil hati. Paulus mengingatkan kita bahwa "penderitaan zaman sekarang ini tidak dapat dibandingkan dengan kemuliaan yang akan dinyatakan kepada kita" (Rom.8:18). Dan yang lebih penting adalah janji Kristus kepada gereja milik 
kepunyaan-Nya: "Aku akan mendirikan jemaatKu dan alam maut tidak akan menguasainya" (Mat.16:18) dan "Aku menyertai kamu senantiasa sampai kepada akhir zaman." Untuk itu, selama masih diberikan kepercayaan oleh Kristus, gereja-gereja Indonesia harus menjalankan tugas panggilannya dengan setia dan sukacita. Tuhan menguatkan dan menolong gereja-Nya di Indonesia. 